\title{
Carotid artery stiffness measured by strain elastography ultrasound is a stroke risk factor
}

\author{
Anastasia Tjan $^{\text {a }}$, I. Gde Raka Widiana ${ }^{\mathrm{b}}$, Elysanti Dwi Martadiani ${ }^{\mathrm{a}, *}$, \\ I. Made DwijaPutra Ayusta ${ }^{a}$, Made Widhi Asih ${ }^{a}$, Firman Parulian Sitanggang ${ }^{a}$ \\ ${ }^{a}$ Radiology Department, Universitas Udayana Faculty of Medicine- Sanglah General Hospital, Jl. Diponegoro, Dauh Puri Klod, Kec. Denpasar Bar., Kota Denpasar, Bali, \\ 80113, Indonesia \\ ${ }^{\mathrm{b}}$ Internal Medicine Department, Universitas Udayana Faculty of Medicine- Sanglah General Hospital, Jl. Diponegoro, Dauh Puri Klod, Kec. Denpasar Bar., Kota \\ Denpasar, Bali, 80113, Indonesia
}

\section{A R T I C L E I N F O}

\section{Keywords:}

Ultrasound

Strain elastography

Carotid artery

Stroke

Arterial aging

\begin{abstract}
A B S T R A C T
It has been known that carotid stiffness is a predilection for stroke. Strain elastography (SE) ultrasound (US) is one of the new modalities which can evaluate carotid artery stiffness by obtaining its tunica intima media strain value. There were no studies that show the carotid artery SE US value in stroke patients, hence become the underlying reason this study was conducted. The aim of this study was to provide an evaluation of carotid artery SE US values in stroke patients.

A pair-matched case-control study was conducted on 40 case subjects and 40 controls which met all inclusion and exclusion criteria. Carotid arteries SE US value was obtained through the average of 3 region of interest (ROI) on each intima media layer of 3 level carotid arteries assessed on both sides. Diagnostic accuracy study was analysed to determine the cut off value between stiff and not stiff. Subsequently, bivariate and multivariate analyses were performed.

There were $65 \%$ male on both groups with mean age $56.7 \pm 13.0$ on the case group and $53.8 \pm 11.8$ on the control group. ROC curve analysis showed that all measurement locations were reliable with high numbers (91.03-97.8\%). The cut of value of carotid artery stiffness was $\geq 0.9333$ ( $97.5 \%$ sensitivity and $90 \%$ specificity). Carotid artery stiffness is a major risk factor of stroke with OR 351 (p value 0.000). Multivariate analysis showed that carotid artery stiffness remained a strong risk factor of stroke (OR 467.89, p value 0,000). Other radiologist can repeat this technique with good interobserver $(\mathrm{r}=0.782-0.985)$ and intraobserver reliability $(\mathrm{r}=$ 0.802-0.954).

Carotid artery stiffness is a strong risk factor for stroke, with carotid artery stiffness SE US cut off values of $\geq 0.9333$.
\end{abstract}

\section{Introduction}

Stroke is a major worldwide problem that causes high mortality and morbidity. Based on Global Burden of Disease in Asia, East Asia and South Asia, Indonesia placed second as the highest stroke death case country with approximately 193.3/100.000 persons/year and ranked second highest with stroke related disabilities with a burden of 3.382/ 100.000 persons in 2010.

There are many risk factors that are known for stroke. The incidence of stroke doubling after the age of 55 years old, but it is said to be higher at younger ages in women, but higher at older age in men. Pregnancy is one of the risk factors of stroke in women, it can be caused by preeclampsia, hormonal therapy or contraceptive mediation. Atrial fibrillation is well known as the major risk factor of stroke, due to the irregular high pulse that can cause embolus to travel in cerebrovascular vasculature and causing stroke. ${ }^{2}$ Physical inactivity also contributes to stroke, it is often correlated with dyslipidemia, diabetes mellitus, and obesity, nevertheless, all of them are a modifiable stroke risk factors. ${ }^{2,3}$ Inflammation and infection are also correlated with a higher incidence of stroke. Inflammation induces earlier changes that contribute to

\footnotetext{
* Corresponding author.

E-mail addresses: anz.4191@gmail.com (A. Tjan), rakawidiana@yahoo.com (I.G.R. Widiana), elysantidm@unud.ac.id (E.D. Martadiani), dp.ayusta@gmail.com (I.M.D. Ayusta), widhiasih123@gmail.com (M.W. Asih), firmandsr@yahoo.com (F.P. Sitanggang).
} 
arterial wall structural formation which then lead to stroke. ${ }^{4}$

Another risk factor of stroke is carotid stiffness. Several studies had pointed out, the presence of carotid artery stiffness correlated with the incident of stroke. ${ }^{2,5-9}$ There are many factors that can lead to arterial stiffness, but overall aging, inflammation, and cardiovascular disease are the risk factors of arterial stiffness. A prior study has shown that carotid artery stiffness is associated with higher stroke incidence independently of cardiovascular factors, sex, and age. ${ }^{6}$

Carotid artery stiffness results in impaired function as an elastic cushion against blood flow ${ }^{5}$ resulting in an increase systolic pressure, decreasing coronary artery perfusion and increasing flow load on the microcirculation, which can lead to stroke $\mathrm{e}^{10}$

There are various mechanisms which elaborate the relationship between arterial stiffness and stroke. An increased pulse pressure will cause arterial remodeling, which leads to arterial wall thickening, and then motivate plaque formation and atherosclerosis, which resulted in rupture or ulceration of the atherosclerotic plaque. As main artery stiffness increases, the capacity for pulsatile flow regulation automatically reduces, leading to progressive impendence between the aorta and peripheral arteries. These impedances will provoke the decreased vascular resistance in the brain and impair cerebral microvascular and cognitive function. In a nut shell, Carotid artery stiffness can affect its function as elastic cushion against blood flow impaired, ${ }^{5}$ which then leads to stroke. ${ }^{10}$

Central artery stiffness is a parallel reflection of intracerebral vascular structural changes including breakdown of elastic fibre, fibrosis, calcification, necrosis of medial smooth muscle, and diffusion of macromolecules into arterial walls. ${ }^{8}$ Therefore, the classic risk factors for vascular disease such as hypertension, atherosclerosis, coronary heart disease, and end-stage kidney disease related to arterial stiffness, are also risk factors for stroke.

Ultrasound elastography of the carotid arteries is a proposed technique for investigating vascular disorders that contribute as a risk factor for vascular disease, especially cerebrovascular, such as carotid artery stiffness and evaluation of plaque in the carotid arteries. ${ }^{11-13}$ Two major types of ultrasound elastography are strain and shear, however the use of shear wave ultrasound is still limited in our centre, hence the use of ultrasound strain elastography (USE) was used in this research.

Ultrasound strain elastography (USE) is a promising method for assessing tissue elasticity qualitatively and semi quantitatively by applying compression or stress via an ultrasound probe externally by the operator, physiological pulses or movements of patient's body. The stress exerted through the transducer is applied continuously by means of compression - decompression to the patient's body surface so that the ultrasound data can record the radiofrequency changes after and before compression. ${ }^{14}$

Several previous studies have suggested the association between carotid artery stiffness and stroke using various methods, ${ }^{5,15}$ but some other studies showed no significant relationship between the two, due to small sample size and lots of bias. ${ }^{2,7,8}$

This study was conducted through a limited study that revealed the value of carotid artery USE in stroke patients and its value in non stroke individuals, as well as the lack carotid stiffness USE study in Indonesia, which contributes lots of stroke caused death and disability count throughout Asia. Therefore, this study aimed to give referral value of the carotid artery USE in stroke patients.

\section{Method}

The study was approved by the Ethics Committee of Sanglah General Hospital, Universitas Udayana. Written informed consent was obtained from the participants or family before the examination begun.

This research is a pair matched case control study to evaluate the ultrasound value of carotid artery USE in stroke patients compared to non-stroke individuals. This study began by identifying the case group, namely stroke patients, then looking for the match from the control group (non-stroke patient) who has similar age and the same gender. The study sample, pair matching, was selected in pairs with age criteria that did not have a difference of more than 5 years and had the same sex. Cases and controls were collected one by one and each time they got one case, their partner was chosen to be a control that had characteristics as described.

The inclusion criteria for this study were all subjects who presented at emergency department at our center the stroke manifestation that persisted for more than $24 \mathrm{~h}$, either ischemic or haemorrhagic stroke, who agreed and signed the informed consent. Unstable patients with decreased level of consciousness and ventilator dependent patient who was admitted to the intensive care department were all excluded. Stroke patient due to underlying diseases such as malignancy, infection, vasculitis, and haematological disorders were also excluded.

USE was performed on both right and left carotid arteries using a 12 $\mathrm{mHz}$ linear probe by selecting the elastography mode on GE Loqic S7 Expert ultrasound machine where there was a superposition of colour on the grey scale ultrasound image. Blue indicates denser areas and red is more elastic or soft. Compression was not applied externally, instead it was obtained physiologically using pulses movement that giving contraction and relaxation movement of the arterial wall. Physiological compression was considered sufficient when it reached at least the 5th green bar. The strain value analysis was obtained by placing the 3 ROIs on intima media complex of each area assessed which were the common carotid artery, bulb, and internal carotid artery C1, then the three ROI strains were averaged to get the strain value of each area. It means each right and left had 3 strain average values, therefore there were 6 strain values in total of each patient, right common carotid artery (RCCA), right bulb (RBULB), right internal carotid artery C1 (RICA), left common carotid artery (LCCA), left bulb (LBULB), and left internal carotid artery C1 (LICA) (Fig. 1).

Carotid artery evaluation was performed at 3 locations on each side, 6 locations in total, namely the common carotid artery, which was measured $2 \mathrm{~cm}$ from the carotid artery bifurcation, carotid artery bulb, and internal carotid artery $\mathrm{C} 1$ that performed at $1 \mathrm{~cm}$ distal to the carotid artery bulb. Grey scale B-mode ultrasound was used to evaluate the presence of thrombus and intima media thickness of the entire carotid artery assessed. Intima media thickness (IMT) is defined if the average measurement was $\geq 0.9 \mathrm{~mm},{ }^{16,17}$ while the presence of thrombus was defined if there was any local arterial wall protrusion of plaque that extent within the lumen more than equal to $1.5 \mathrm{~mm}$ or thickening of intima media more than $50 \%$ from its normal adjacent intima media structure. $^{18}$

All results were recorded and ultrasound images obtained via the PACS system. Then the complete data were analysed with the STATA 14.2 program. The first step was determining the cut off value using receiver operating characteristic (ROC) curve to achieve the USE cut off value between stiff and non-stiff carotid arteries, afterwards analysing Odds ratio and multivariate analysis of the confounding variables studied such as hypertension, diabetes mellitus, smoking, obesity, and dyslipidaemia. The moderator variables studied were intima medial thickness and the presence of thrombus.

\section{Result}

A total of 80 cases collected, 40 subjects in stroke group and 40 subjects in control group, $65 \%$ male predominant $(n=26)$ and $35 \%$ female $(n=14)$, throughout July 2019 to January 2020 . The mean age in case group was $56.7 \pm 13.0$ years old range from 35 to 85 , while the mean age in the control group was $53.8 \pm 11.8$ range from 34 to 80 years old (Table 1).

Two-blinded experienced radiologist conducted USE, with interobserver variability $0.782-0.985$ and intraobserver variability 0.802-0.954 did USE examination.

The receiver operating characteristic (ROC) curve showed all 12 values examined from each subjects USE RCCA value had the best result 

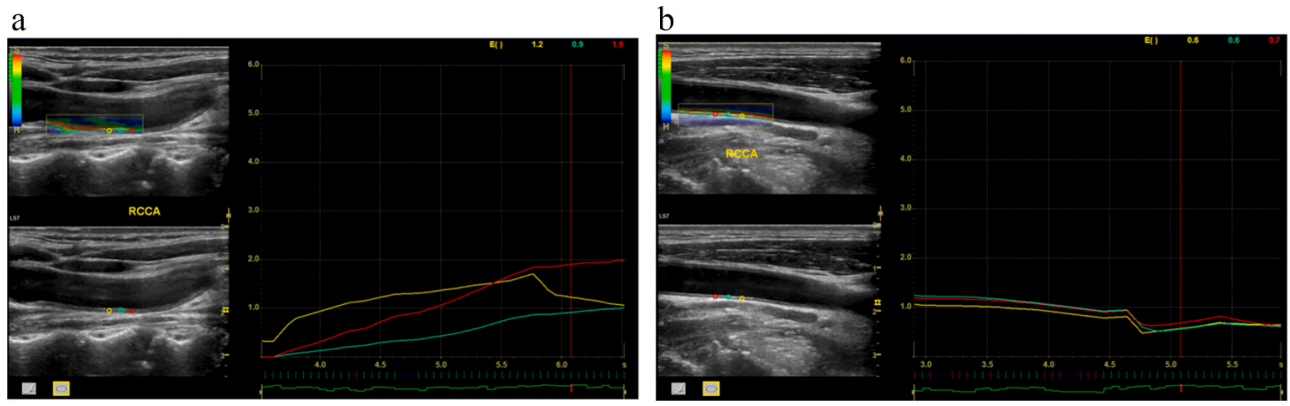

Fig. 1. USE Right Common Carotid Artery. Good physiological compression determined by the green bar on top left of the screen. Placing 3 ROI on intima media complex of RCCA to get the average strain value of the location. (a) Example of one subject on case group which shows a high strain value. (b) Example of one subject on control group, the strain value is low.

Table 1

Baseline characteristic of the study.

\begin{tabular}{lll}
\hline Variables & Group & \\
\cline { 2 - 3 } & Case & Control \\
\hline Age (year), mean \pm SD & $56.7 \pm 13$ & $53.8 \pm 11.8$ \\
Sex & & \\
$\quad$ Male n (\%) & $26(65 \%)$ & $26(65 \%)$ \\
$\quad$ Female n (\%) & $14(35 \%)$ & $14(35 \%)$ \\
Smoking n (\%) & $16(40 \%)$ & $9(22.5 \%)$ \\
Nutritional status n (\%) & & \\
$\quad$ Normal & $15(37.5 \%)$ & $28(70 \%)$ \\
Overweight & $11(27.5 \%)$ & $10(25 \%)$ \\
$\quad$ Pre-obese & $12(30 \%)$ & $1(2.5 \%)$ \\
$\quad$ Obese & $2(5 \%)$ & $7(2.5 \%)$ \\
Hypertension n (\%) & $28(70 \%)$ & $0(0 \% .5 \%)$ \\
Arrhythmia n (\%) & $16(40 \%)$ & $2(5 \%)$ \\
Diabetes mellitus n (\%) & $16(40 \%)$ & $1(2.5 \%)$ \\
Dyslipidaemia n (\%) & $26(65 \%)$ & \\
\hline
\end{tabular}

of 0.978 (Fig. 2). Therefore, USE RCCA value was used as the cut-off value of carotid artery stiffness. The carotid artery was stiff if the USE RCCA value was $\geq 0.9333$, sensitivity of $97.5 \%$, and specificity of $90 \%$.

The cut off value was used to determine the relationship between stroke and carotid artery stiffness. Total of $39(97.5 \%)$ subjects were stiff in case group, while only 4 (10\%) subjects were stiff on control group.

Carotid artery stiffness is the risk of stroke with Odds Ratio (OR) $351.95 \%$ CI (OR) 34.7-14569, P = 0.000 (Table 2).

Multivariate analysis was done to control confounding variables such

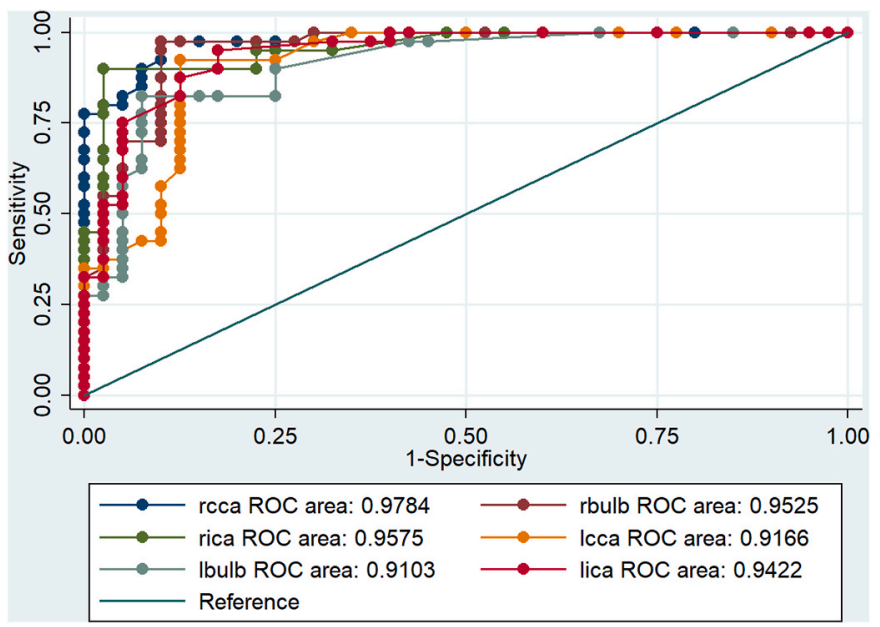

Fig. 2. ROC Curve of USE Carotid Artery. All 6 areas of carotid artery measured in this study showed values above $90 \%$. However, RCAA has the best value, which is $97,84 \%$, therefore RCCA is used as the cut-off point to determine stiffness.
Table 2

Cross tabulation analysis of carotid artery stiffness and stroke.

\begin{tabular}{llllll}
\hline & \multicolumn{2}{l}{ Carotid Artery Stiffness } & & Total & \\
\cline { 2 - 3 } & + & - & & \\
\hline Case & 39 & 1 & 40 & \\
Control & 4 & 36 & & 40 & \\
Total & 43 & 37 & & 80 & \\
& OR & & $95 \%$ CI (OR) & \\
& 351 & & 34.7 & 14569.5 \\
& $\mathrm{P}=0.000$ & & & \\
\hline
\end{tabular}

as hypertension, diabetes mellitus, smoking, obesity, and dyslipidaemia. Logistic regression test gave result in OR $>1$ with $\mathrm{p}>0.05$, hence explaining that there was a strong correlation between the independent variables. Based on the result, dyslipidaemia showed significant correlation with carotid artery stiffness with OR 24.3, therefore another multivariate analysis was done without dyslipidaemia, and gave a significant result OR 467.89, $\mathrm{P}=0.000$. (Table 3).

The presence of thrombus on carotid artery and intima medial thickness were analysed on this study. We found as many as 20 subjects had thrombus on one or both carotid artery and 20 subjects had no thrombus on case group, while on control group only 1 subject had thrombus. The presence of thrombus is certainly a risk factor of stroke with OR 39, $\mathrm{p}=0.000$ (95\% CI 5.25-1656). Another additional result was found on this study that a thick intima media increased the risk of stroke (Table 4).

\section{Discussion}

This study showed that arterial stiffness is indeed the risk factor of stroke, which can be proven by measuring local artery using USE. Demographically, this research is similar to other literature, male predominant and older age group were predominant for stroke incidence. ${ }^{19,20}$ It is well known that several comorbidities are the independent risk factor of stroke. ${ }^{21,22}$ As expected, hypertension, diabetes mellitus, arrhythmia, dyslipidaemia, overweight/obese, smoking, and sedentary lifestyle were found dominant on stroke cases.

A previous study also demonstrated patient who is inactive physically have stiffer arteries rather than physically active people. Another prior study showed patient that has controlled hypertension with medication had reduced arterial stiffness. This proves that hypertension and sedentary lifestyle both are the risk factor for stroke, which correlated with stiffer artery. ${ }^{2}$

ROC curve of all sites of carotid artery were calculated and all of them showed good ability to predict the occurrence of stroke (91.03-97.8\%). However, RCCA demonstrated the highest score (97.8\%). The cut off value used for arterial stiffness was $\geq 0.9333$ (sensitivity $97.5 \%$, specificity $90 \%$ ).

As hypothesized, carotid arterial stiffness measured by USE RCCA 
Table 3

Multivariate analysis.

\begin{tabular}{|c|c|c|c|c|c|c|}
\hline Group & OR & Std Err & $\mathrm{Z}$ & $\mathrm{P}>|\mathrm{z}|$ & 95\% CI (OR) & \\
\hline Carotid artery stiffness & 467.8935 & 689.8911 & 4.17 & 0.000 & 26.00655 & 8418.046 \\
\hline Hypertension & 2.653921 & 2.727596 & 0.95 & 0.342 & 0.3540433 & 19.89388 \\
\hline Diabetes mellitus & 5.20445 & 8.041725 & 1.07 & 0.286 & 0.2518428 & 107.5524 \\
\hline Smoking & 0.2428232 & 0.2967091 & -1.16 & 0.247 & 0.0221409 & 2.663088 \\
\hline Overweight-obese & 1.307378 & 0.8489621 & 0.41 & 0.680 & 0.3661533 & 4.668092 \\
\hline
\end{tabular}

Table 4

Intima media thickness (IMT) and carotid artery stiffness.

\begin{tabular}{|c|c|c|c|c|c|c|}
\hline \multirow[t]{2}{*}{ IMT } & \multicolumn{2}{|c|}{ Control n (\%) } & \multicolumn{2}{|c|}{ Case n (\%) } & \multirow[t]{2}{*}{$\mathrm{OR}(\mathrm{p}=)$} & \multirow[t]{2}{*}{$95 \%$ CI } \\
\hline & Normal & Thick & Normal & Thick & & \\
\hline RCCA & $\begin{array}{l}31 \\
(77.5)\end{array}$ & $\begin{array}{l}9 \\
(22.5)\end{array}$ & $\begin{array}{l}15 \\
(37.5)\end{array}$ & $\begin{array}{l}25 \\
(62.5)\end{array}$ & $\begin{array}{l}5.74 \\
(0.00)\end{array}$ & $1.95-17.4$ \\
\hline RBULB & $28(70)$ & $12(30)$ & $8(20)$ & $32(80)$ & $\begin{array}{l}9.33 \\
(0.00)\end{array}$ & $3.01-30.1$ \\
\hline RICA & $38(95)$ & $2(5)$ & $30(75)$ & $10(25)$ & $\begin{array}{l}6.33 \\
(0.01)\end{array}$ & $1.2-62.41$ \\
\hline LCCA & $32(80)$ & $8(20)$ & $20(50)$ & $20(50)$ & $4(0.00)$ & $1.35-12.42$ \\
\hline LBULB & $32(80)$ & $8(20)$ & $12(30)$ & $28(70)$ & $\begin{array}{l}9.33 \\
(0.00)\end{array}$ & $3.01-30.1$ \\
\hline LICA & $\begin{array}{l}37 \\
(92.5)\end{array}$ & $3(7.5)$ & $\begin{array}{l}25 \\
(62.5)\end{array}$ & $\begin{array}{l}15 \\
(37.5)\end{array}$ & $\begin{array}{l}7.4 \\
(0.00)\end{array}$ & $1.8-43$ \\
\hline
\end{tabular}

has the capability to predict stroke incidence and is a strong risk factor of stroke (Odds Ratio (OR): 351 , $\mathrm{p}$ value $=0.000$ ). There are many supporting prior literatures that showed arterial stiffness is a stroke predictor and risk factor. ${ }^{9,23,24}$ Arterial stiffness can be caused by many underling process, all diseases that causing endothelial dysfunction and affects extracellular matrix remodeling will turn to stiffening of the artery and contribute to stroke. Confounding variables must be controlled to see the relationship of stroke and carotid arterial stiffness clearly. The first multivariate analysis exposed a strong direct relationship between independent variables, dyslipidaemia and carotid arterial stiffness, which affect the result. Hence, another multivariate analysis was done without dyslipidaemia on the variable list, and the result validated that carotid arterial stiffness is a strong risk factor of stroke, OR 467.89, $\mathrm{p}=$ 0.000 . Dyslipidemia dramatically increases arterial stiffness by activating endothelial contractility, oxysterols accumulation on endothelial layer, increases inflammation mediator, ${ }^{25}$ mitochondrial disfunction, stress oxidatie which directly impacts the necrosis and apoptosis of endothelial cell. ${ }^{26}$

It is a common knowledge that arterial aging leads to thickening of intima media complex and thrombus formation which all can cause stroke. Several prior studies have mentioned that IMT is associated with stroke event, ${ }^{27-30}$ and revealed that carotid plaque is an independent predictor of stroke. ${ }^{31}$ As presented on this study, the presence of thrombus and IMT are risk factor of stroke with $\mathrm{OR}>1, \mathrm{p}<0.05$. It has been acknowledged by previous studies that increased IMT correlate with generalized atherosclerosis. Rotterdam study mentioned both carotid stiffness and IMT related to plaque thickness. ${ }^{17}$

Fibrosis, calcification, and break in elastin fibers are all the basic components in the thickening of intima-media and plaque formation as well as carotid stiffness. The structural elasticity changes of the carotid artery will prone to plaque rupture and plaque ulceration, which then causes stroke. ${ }^{2}$ It is like choosing between egg or chicken first, everything can happen simultaneously, but this study it is proven that carotid arterial stiffness is the major risk of stroke along with other risk factors such as IMT and the presence of plaque, however, carotid artery stiffness measured by USE has greater OR, which means greater contribution as a stroke risk factor. ${ }^{17}$

The use of this study is to evaluate the presence of carotid arterial stiffness which leads to stroke. Other than well-known modifiable and non-modifiable stroke risk factors, several other diseases can lead to stroke such as HIV and the currently hyped virus, COVID-19. It was found that the carotid artery wall was stiffer, with higher axial strains on USE, and with more presence of carotid plaque, in a patient infected with HIV, even though they have been treated with antiretroviral. ${ }^{4}$ In this pandemic era, it has also been found that COVID-19 increase risk of stroke, this is due to several various mechanisms such as prothrombotic state, changes in lipid metabolism, and platelet aggregation, alteration in endothelial function and plaque instability as well as rupture, which all change the structural integrity of the arterial wall, lead to arterial stiffness and causes stroke. ${ }^{32}$

USE is non-invasive, local, direct, real-time imaging that can be used to measured arterial stiffness as the stroke risk factor.

This study has several limitations as stated below.

The use of only one type of ultrasound may affect the result due to different precision of each manufacturer. A universal standard should be developed and applied to all machines, to calibrate the system in each devices.

Elastography is one of sophisticated tools in radiology. Due to its vast development, strain elastography has recently been replaced with shear wave elastoraphy, which is more quantitative in nature and less subjectivity. However, the program itself is still limited in our country. In contrary, the use of shear wave elastography has appeared in most journal publication in the world.

There was discrepancy between peripherally measured blood pressure (BP) for hypertension and centrally measured arterial stiffness on carotid artery. As we know, there is amplification between peripheral and central BP, moreover on younger subject. Luckily this study sample was old age group predominant.

All of our limitation should be used for further study.

\section{Conclusion}

Carotid arterial stiffness can be determined by using USE, a noninvasive technique. USE of the RCCA can determine carotid arterial stiffness with cut-off value of $\geq 0.9333$, which is a strong predictor and a risk factor of stroke.

\section{Appendix A. Supplementary data}

Supplementary data to this article can be found online at https://doi. org/10.1016/j.cegh.2021.100850.

\section{References}

1 Venketasubramanian N, Yoon BW, Pandian J, Navarro JC. Stroke epidemiology in south, east, and south-east asia: a review. J Stroke. 2017;19:286-294. https://doi. org/10.5853/jos.2017.00234.

2 Dijk JM, van der Graaf Y, Grobbee DE, Bots ML. Carotid stiffness indicates risk of ischemic stroke and TIA in patients with internal carotid artery stenosis: the SMART study. Stroke. 2004;35:2258-2262. https://doi.org/10.1161/01. STR.0000141702.26898.e9.

3 Kuriakose D, Xiao Z. Pathophysiology and treatment of stroke: present status and future perspectives. Int J Mol Sci. 2020;21:1-24. https://doi.org/10.3390/ ijms21207609.

4 Roy Cardinal MH, Durand M, Chartrand-Lefebvre C, et al. Increased carotid artery wall stiffness and plaque prevalence in HIV infected patients measured with ultrasound elastography. Eur Radiol. 2020;30:3178-3187. https://doi.org/10.1007/ s00330-020-06660-9. 
5 van Sloten TT, Sedaghat S, Laurent S, et al. Carotid stiffness is associated with incident stroke A systematic review and individual participant data meta-analysis. J Am Coll Cardiol. 2015;66:2116-2125. https://doi.org/10.1016/j.jacc.2015.08.888.

6 van Sloten TT, Sedaghat S, Laurent S, et al. Carotid stiffness is associated with incident stroke A systematic review and individual participant data meta-analysis. J Am Coll Cardiol. 2015;66:2116-2125. https://doi.org/10.1016/j.jacc.2015.08.888.

7 Van Sloten TT, Schram MT, Van Den Hurk K, et al. Local stiffness of the carotid and femoral artery is associated with incident cardiovascular events and all-cause mortality: the hoorn study. J Am Coll Cardiol. 2014;63:1739-1747. https://doi.org/ 10.1016/j.jacc.2013.12.041.

8 Mattace-Raso FUS, Van Der Cammen TJM, Hofman A, et al. Arterial stiffness and risk of coronary heart disease and stroke: the Rotterdam Study. Circulation. 2006;113: 657-663. https://doi.org/10.1161/CIRCULATIONAHA.105.555235.

9 Chen Y, Shen F, Liu J, Yang GY. Arterial stiffness and stroke: de-stiffening strategy, a therapeutic target for stroke. Stroke Vascul Neurol. 2017;2:65-72. https://doi.org/ 10.1136/svn-2016-000045.

10 van Sloten TT, Stehouwer CDA. Carotid stiffness: a novel cerebrovascular disease risk factor. Pulse. 2016;4:24-27. https://doi.org/10.1159/000445354.

11 Nayak R, Huntzicker S, Ohayon J, et al. Principal strain vascular elastography: simulation and preliminary clinical evaluation. Ultrasound Med Biol. 2017;43: 682-699. https://doi.org/10.1016/j.ultrasmedbio.2016.11.010.

12 Nieuwstadt HA, Fekkes S, Hansen HHG, et al. Carotid plaque elasticity estimation using ultrasound elastography, MRI, and inverse FEA - a numerical feasibility study. Med Eng Phys. 2015;37:801-807. https://doi.org/10.1016/j. medengphy.2015.06.003.

13 Maurice RL, Soulez G, Giroux MF, Cloutier G. Noninvasive vascular elastography for carotid artery characterization on subjects without previous history of atherosclerosis. Med Phys. 2008;35:3436-3443. https://doi.org/10.1118/ 1.2948320 .

14 Mahmood B, Ewertsen C, Carlsen J, Nielsen M. Ultrasound vascular elastography as a tool for assessing atherosclerotic plaques - a systematic literature review. Ultrasound Int Open. 2016;2:E106-E112. https://doi.org/10.1055/s-0042-115564.

15 Yang EY, Chambless L, Sharrett AR, et al. Carotid arterial wall characteristics are associated with incident ischemic stroke but not coronary heart disease in the Atherosclerosis Risk in Communities (ARIC) Study. Stroke. 2012;43:103-108. https://doi.org/10.1161/STROKEAHA.111.626200.

16 Paul J, Shaw K, Dasgupta S, Ghosh MK. Measurement of intima media thickness of carotid artery by B-mode ultrasound in healthy people of India and Bangladesh, and relation of age and sex with carotid artery intima media thickness: an observational study. J Cardiovasc Dis Res. 2012;3:128-131. https://doi.org/10.4103/09753583.95367.

17 Harloff A, Strecker C, Reinhard M, et al. Combined measurement of carotid stiffness and intima-media thickness improves prediction of complex aortic plaques in patients with ischemic stroke. Stroke. 2006;37:2708-2712. https://doi.org/10.1161/ 01.STR.0000244763.19013.dc.
18 Casadei A, Floreani M, Catalini R, Serra C, Assanti AP, Conci P. Sonographic characteristics of carotid artery plaques: implications for follow-up planning? J Ultrasound. 2012;15:151-157. https://doi.org/10.1016/j.jus.2012.06.002.

19 Meirhaeghe A, Cottel D, Cousin B, et al. Sex differences in stroke attack, incidence, and mortality rates in northern France. J Stroke Cerebrovasc Dis. 2018;27:1368-1374. https://doi.org/10.1016/j.jstrokecerebrovasdis.2017.12.023.

20 Kusuma Y, Venketasubramanian N, Kiemas LS, Misbach J. Burden of stroke in Indonesia. Int J Stroke. 2009;4:379-380. https://doi.org/10.1111/j.17474949.2009.00326.x.

21 Boehme A, Esenwa Me C. Stroke: risk factors and prevention. JPMA (J Pak Med Assoc). 2018;60:412. https://doi.org/10.1161/CIRCRESAHA.116.308398.Stroke.

$22 \mathrm{Li} \mathrm{RC,} \mathrm{Xu} \mathrm{WD,} \mathrm{Lei} \mathrm{YL,} \mathrm{et} \mathrm{al.} \mathrm{The} \mathrm{risk} \mathrm{of} \mathrm{stroke} \mathrm{and} \mathrm{associated} \mathrm{risk} \mathrm{factors} \mathrm{in} \mathrm{a} \mathrm{health}$ examination population: a cross-sectional study. Medicine (United States). 2019;98. https://doi.org/10.1097/MD.0000000000017218.

23 Saeed S, Waje-Andreassen U, Fromm A, et al. Early vascular aging in young and middle-aged ischemic stroke patients: the Norwegian stroke in the young study. PloS One. 2014;9:1-6. https://doi.org/10.1371/journal.pone.0112814.

24 Tsai WC, Sun YT, Liu YW, et al. Usefulness of vascular wall deformation for assessment of carotid arterial stiffness and association with previous stroke in elderly. Am J Hypertens. 2013;26:770-777. https://doi.org/10.1093/ajh/hpt027.

25 Master E Le, Levitan I. In: Stiffness of the Vascular Wall. 11. 2019:9-10.

26 Kim JA, Montagnani M, Chandrasekran S, Quon MJ. Role of lipotoxicity in endothelial dysfunction. Heart Fail Clin. 2012;8:589-607. https://doi.org/10.1016/j. hfc. 2012.06.012.

27 Geisel MH, Bauer M, Hennig F, et al. Comparison of coronary artery calcification, carotid intima-media thickness and ankle-brachial index for predicting 10-year incident cardiovascular events in the general population. Eur Heart J. 2017;38: 1815-1822. https://doi.org/10.1093/eurheartj/ehx120.

28 Sahoo R, Krishna MV, Subrahmaniyan DKS, Dutta TK, Elangovan S. Common carotid intima-media thickness in acute ischemic stroke: a case control study. Neurol India. 2009;57:627-630. https://doi.org/10.4103/0028-3886.57822.

29 Polak JF, Pencina MJ, O'Leary DH, D'Agostino RB. Common carotid artery intimamedia thickness progression as a predictor of stroke in multi-ethnic study of atherosclerosis. Stroke. 2011;42:3017-3021. https://doi.org/10.1161/ STROKEAHA.111.625186.

30 Ohira T, Shahar E, Iso $\mathrm{H}$, et al. Carotid artery wall thickness and risk of stroke subtypes: the atherosclerosis risk in communities study. Stroke. 2011;42:397-403. https://doi.org/10.1161/STROKEAHA.110.592261.

31 Yoon HJ, Kim KH, Park H, et al. Carotid plaque rather than intima-media thickness as a predictor of recurrent vascular events in patients with acute ischemic stroke. Cardiovasc Ultrasound. 2017;15:1-8. https://doi.org/10.1186/s12947-017-0110-y.

32 Belani P, Schefflein J, Kihira S, et al. COVID-19 Is an independent risk factor for acute ischemic stroke. Am J Neuroradiol. 2020;41:1361-1364. https://doi.org/ 10.3174/ajnr.A6650. 